\title{
Partitioning of snowy and rainy precipitation in a case of a north Adriatic frontal passage
}

\author{
M. Monai, A. M. Rossa, and A. C. Bonan \\ Meteorological Center of Teolo, ARPA Veneto, Italy \\ Received: 31 October 2005 - Revised: 10 February 2006 - Accepted: 13 February 2006 - Published: 18 April 2006
}

\begin{abstract}
A case of snow fall in the plains of the Northern Italian region Veneto is presented from a forecasters' perspective. Contrasting forecast guidance came from the ECMWF global model and the limited area model LAMI. The former showed a marked warm-moist Sirocco flow coming from the Adriatic Sea onto the coast at all levels, the latter discerned a distinct cold air flow from the north-east along the foothills of the Alps. The integrated observing network of the Centro Meteorologico di Teolo ARPA Veneto revealed this cold-air structure and helped the forecaster in the choice of the forecast and underpin the snowfall alert to the road authorities. It is argued that this feature is a crucial element for the occurrence of snowfall over the Veneto plains, and that the high-resolution numerical weather prediction model was essential in describing this mesoscale feature. The nature of the north-easterly flow is thought to be a combination of a Bora like flow and a barrier jet induced by flow blocking by the Alps.
\end{abstract}

\section{Introduction}

Substantial snowfall is a relatively rare event over the flat plains of the North-eastern Italian region Veneto (see Fig. 1 for its location). Hence, reliable forecast and monitoring of snow is very important for road traffic, including an extended transport system, in order to help to avoid emergency situations. Precipitation in Veneto is frequently linked to an atmospheric flow with a marked southerly component, inducing warm-humid Sirocco winds from the Mediterranean. Cold air, on the other hand, is often tied to cold and dry north-easterly Bora flows onto the region. There is a substantial number of studies on the Bora flows and the dynamical mechanisms involved. Ivancan-Picek and Tutis (1996) and Brzovic (1999), for instance, suggest that the orography of the Mediterranean area, especially the Appennines

Correspondence to: M. Monai

(mmonai@arpa.veneto.it) and the Dinaric Alps surrounding the Adriatic sea channel, is favorable for the Bora and Sirocco-like wind intensification in cases of cyclogenesis over the Po Valley and the northern Adriatic with the cyclone moving southeastward along the Adriatic Sea.

Another mechanism which induces easterly to northeasterly flow on the Veneto plains is tied to what effectively can be called a barrier jet. In such a regime the lower part of a meridional flow is blocked by the orographic Alpine barrier to the north and hence stagnates or is deflected. Recently, Miglietta and Buzzi (2004) showed that a pre-existing cold air pool upstream of the Alps, exhibiting flow reversal, was intensified due to evaporation of precipitation, with precipitation decreased over but substantially enhanced upstream of the mountain. A similar behaviour was documented by several authors for the IOP- 8 of the Mesoscale Alpine Programme (Bougeault et al., 2001).

In this paper attention is given to the partitioning of precipitation types in a case of a frontal passage in the Northern Adriatic. It is argued that the incidence of snowfall on the eastern Po Valley plains can often be the result of a subtle interplay between these southerly and north-easterly flow configurations. The objective is to further the forecaster's conceptual understanding in situations in which a southerly and north-easterly flow co-exist over portions of the Po Valley, and so increase their skill in forecasting the occurrence of snow over the plains. Section 2 describes the data sets used, while in Sect. 3 the case study is presented. A summary with conclusions for the operational setting is given in the final section.

\section{Data sets and methodology}

The present study was performed using operational products as they were available to the bench forecaster. An exception was made for the limited area model (LAM) data, where analyses of the Alpine Model (aLMo), the Lokal Modell (LM) version run by MeteoSwiss were chosen for conve- 


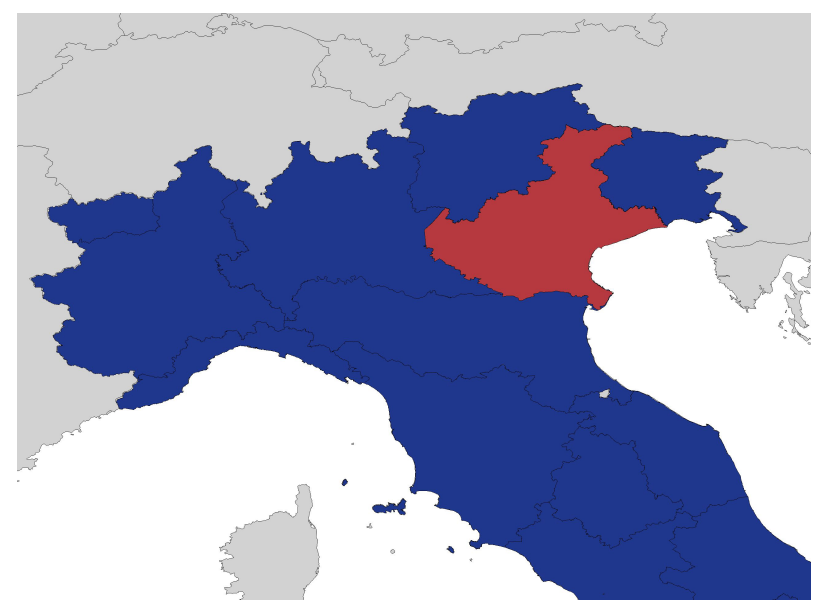

Fig. 1. Veneto is located in the north-eastern part of Italy and borders the Adriatic to its east. Toward the north and the south Veneto is shielded by the Alps and the Appennines, respectively.

nience sake. A detailed description of the LM is available in Doms and Schättler (2004) and Doms et al. (2004). The corresponding forecast product of the Italian LM LAMI, however, were depicting the details of the flow quite accurately. The global model products were taken from the Integrated Forecast System (IFS) of the European Centre for Mediumrange Weather Forecasting (ECMWF) on a Gaussian grid of mesh size $0.5^{\circ}$, while the LAM products came from the Italian version of the Lokal Modell (LAMI) on a grid of $7 \mathrm{~km}$ mesh size.

Observations were available from ARPAV's automatic weather station (AWS) network, which totals roughly 200 stations, the C-band Doppler radar located on Mt. Grande (472 ma.s.l.) on the central part of the Veneto plains, and the Meteosat-8 HRV products. For the present analysis the following observations were used:

- AWS data for two meter temperature $T_{2 \mathrm{~m}}$ and ten meter wind $v_{10 \mathrm{~m}}$ available every hour;

- radar quantitative precipitation estimates (QPE);

- velocity azimuth displays (VAD), i.e. vertical wind profiles as derived from the Mt. Grande radar of ARPAV; and

- Meteosat-8 high-resolution visible (HRV) products for a post-event estimation of the snow coverage in the plains.

The case study approach along with phenomenological description was chosen aiming at documenting the peculiarities of the meteorological situation.

\section{March 2005 snowfall case over Veneto}

\subsection{Numerical forecast guidance}

The case of the Mediterranean cyclone under consideration took place 3 March 2004, when an upper-level trough deep- ened over Western Europe and intruded the Western Mediterranean area in the course of the day, giving rise to a surface lee cyclone in the Gulf of Genoa (not shown). By the end of the day the surface low propagated along the southern fringe of the Alps to the Northern Adriatic, where it was associated with a distinct southerly Sirocco flow.

The ECMWF global model featured a uniform moderate Sirocco flow at all levels of the lower troposphere down the the surface level (Fig. 2 upper panel), hence bringing warmmoist air to the plains. The snowfall limit of this airmass was at several hundreds of meters above sea level, so that a forecast for the Veneto plains (10-20 ma.s.1.) based on the IFS called for rain rather than snow.

The surface conditions as forecast by the LAMI (Fig. 2 lower panel), on the other hand, drew a qualitatively different picture. While the flow in the LAMI was quite similar to the IFS's at $1000 \mathrm{~m}$ above ground (not shown), at $100 \mathrm{~m}$ above ground a marked north-easterly flow emerged. By 3 March 18:00 UTC the surface low was located off the coast of Venice, with a well defined warm frontal signature at the surface along the coast extending east. The warm sector was, therefore, almost entirely confined to the sea, except for the southernmost part of Veneto, confining a cold sector northeasterly flow between the Adriatic and the Alps. Hence, a forecast based on the LAMI included elements necessary for snow to occur on the plains, in that the warm moist Sirocco flow was forced over a layer of cold air thick enough to avoid melting of the precipitation.

The difference between the IFS and the LAMI forecasts becomes even clearer in the vertical cross section (Fig. 3). At 18:00 UTC the thermal contrast between the distinct airmasses was further enhanced, yielding a $10 \mathrm{~K}$ difference in the equivalent potential temperature over some $50 \mathrm{~km}$. Also, it is evident how the warm and moist southerly flow is forced upon the cold air, which effectively acts as a barrier well upstream of the orographical obstacle.

\subsection{Validating observations}

Figure 4 shows the surface observations of the ARPAV AWS network for 3 March 18:00 UTC. Indeed, the $v_{10 \mathrm{~m}}$ evidenced a rather marked north-easterly component, as well as the boundary to the Sirocco flow in the south-eastern corner of Veneto, a flow configuration which persisted for the entire duration of the precipitation event. The $T_{2 \mathrm{~m}}$ field confirmed the cold air in the north-easterly flow and the warm air in the south east.

Moreover, the velocity azimuth display (VAD) of the ARPAV Mt. Grande radar, located some $70 \mathrm{~km}$ from the coast, revealed a distinct low-level jet over the central plain of Veneto with peak values up to $15 \mathrm{~m} / \mathrm{s}$ and north-easterly direction (Fig. 5). Winds decreased with height from the maximum value at $500 \mathrm{~m}$ above ground to $1000 \mathrm{~m}$, where the direction changed gradually to south-easterly, with largest vertical shear values in the lowest levels that the radar can sample. 

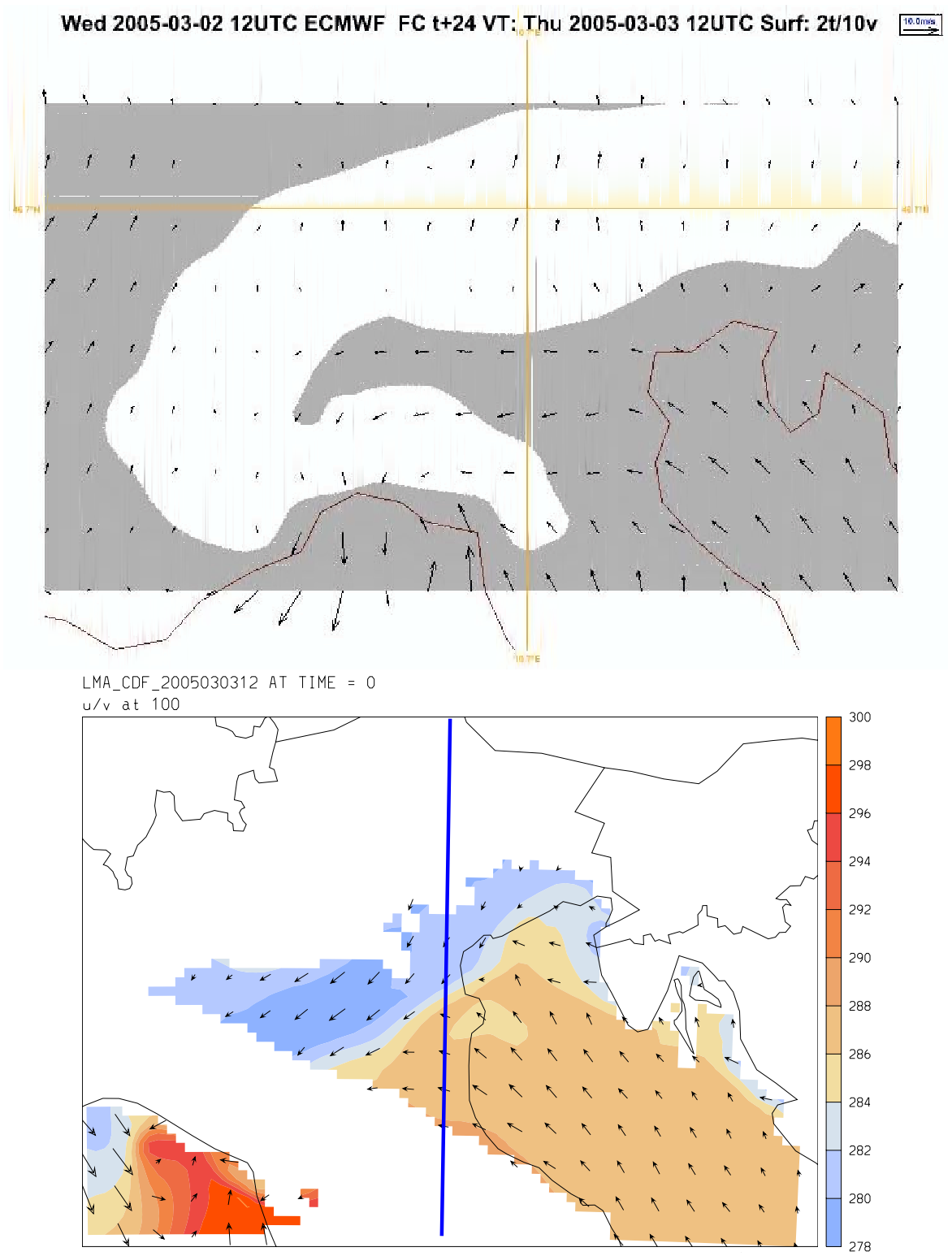

Fig. 2. Upper panels shows ECMWF IFS $+24 \mathrm{~h}$ forecast of the surface conditions valid at 3 March 12 UTC. Shaded areas denote values of the $T_{2} \mathrm{~m}$ above $0^{\circ}$, while the arrows denote the $v_{10} \mathrm{~m}$. Lower panel shows equivalent potential temperature (color shading, contour interval $2 \mathrm{~K}$ ) and horizontal wind vectors at $100 \mathrm{~m}$ a.s.l. as forecast by the LAMI. As a matter of fact, for the sake of convenience, the data shown here are aLMo analyses, which for this case are very close to the LAMI $+12 \mathrm{~h}$ and $+18 \mathrm{~h}$ forecasts. The thick, solid line denotes the position of the vertical cross section shown in Fig. 3, whereas the white areas in denote missing data due to orography which is higher than $100 \mathrm{~m}$.

Figure 6 shows the high-resolution visible image of Meteosat-8 of the following day, i.e. 4 March 12:00 UTC, which very nicely depicts the marks of the snowfall event. Almost the entire Po Valley has been powdered with snow. The southernmost tip of Veneto and the Po Delta, however, received no snow, but rain only, consistent with the wind and temperature observations in Fig. 4, which document that this part was in the warm sector and affected by the Sirocco down to the surface.

\section{Summary and Discussion}

In this paper a case of a Northern Adriatic frontal passage is presented. The focus is placed on giving the forecaster a conceptual understanding of a complex flow situation which can be critical for the occurrence of snow in the Veneto plains. The main findings are as follows:

- the existence of a cold air pool or flow over the Veneto plains, as depicted in the conceptual sketch shown in Fig. 7, is argued to be critical for snow to reach the ground, in that it forces the warm humid air above the 


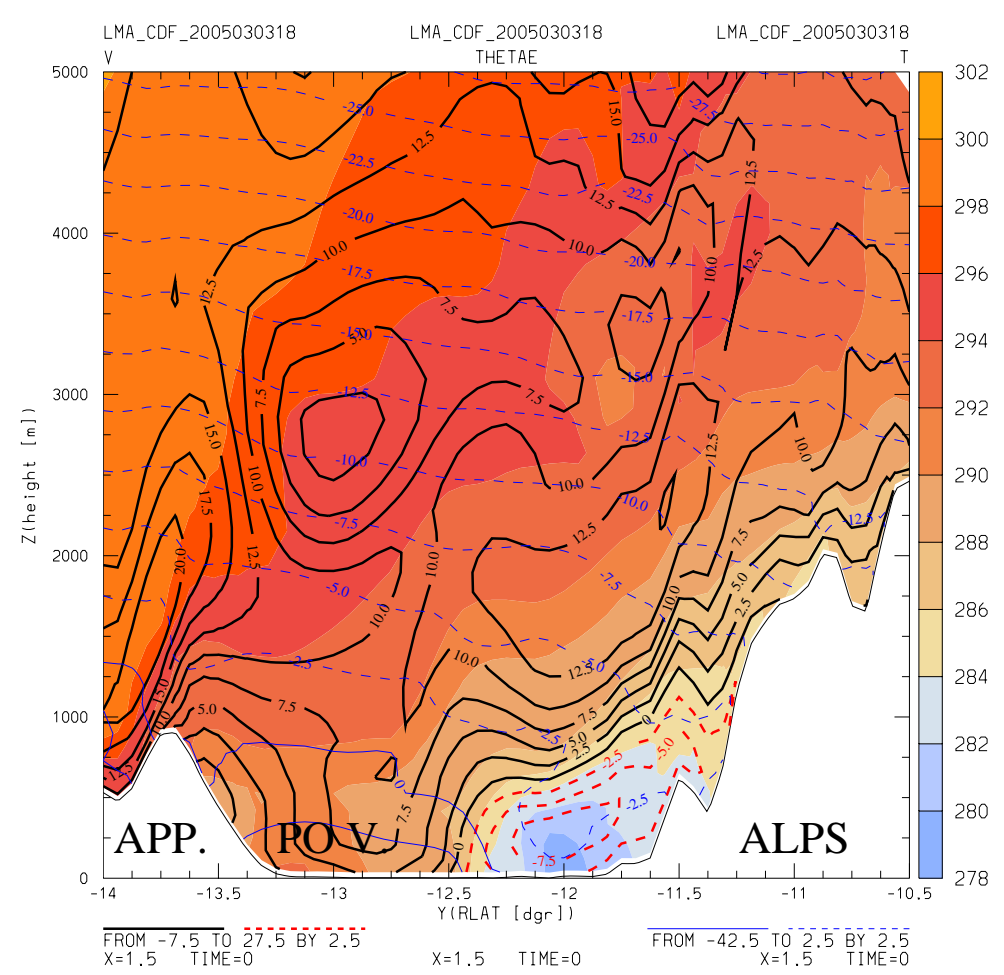

Fig. 3. Vertical cross section as delineated in the lower panel of Fig. 2 of equivalent potential temperature (color shading, contour interval $2 \mathrm{~K}$ ), temperature (thin lines, contour interval $2.5 \mathrm{~K}$, solid/dashed lines above/below $0^{\circ} \mathrm{C}$ ), and meridional wind component (thick lines, contour interval $2.5 \mathrm{~m} / \mathrm{s}$, solid/dashed lines denote a southerly/northerly flow component). The figure stands for the $+18 \mathrm{~h}$ forecast of LAMI valid for 3 March 18:00 UTC, but as in Fig. 2 the data shown here are aLMo analyses.
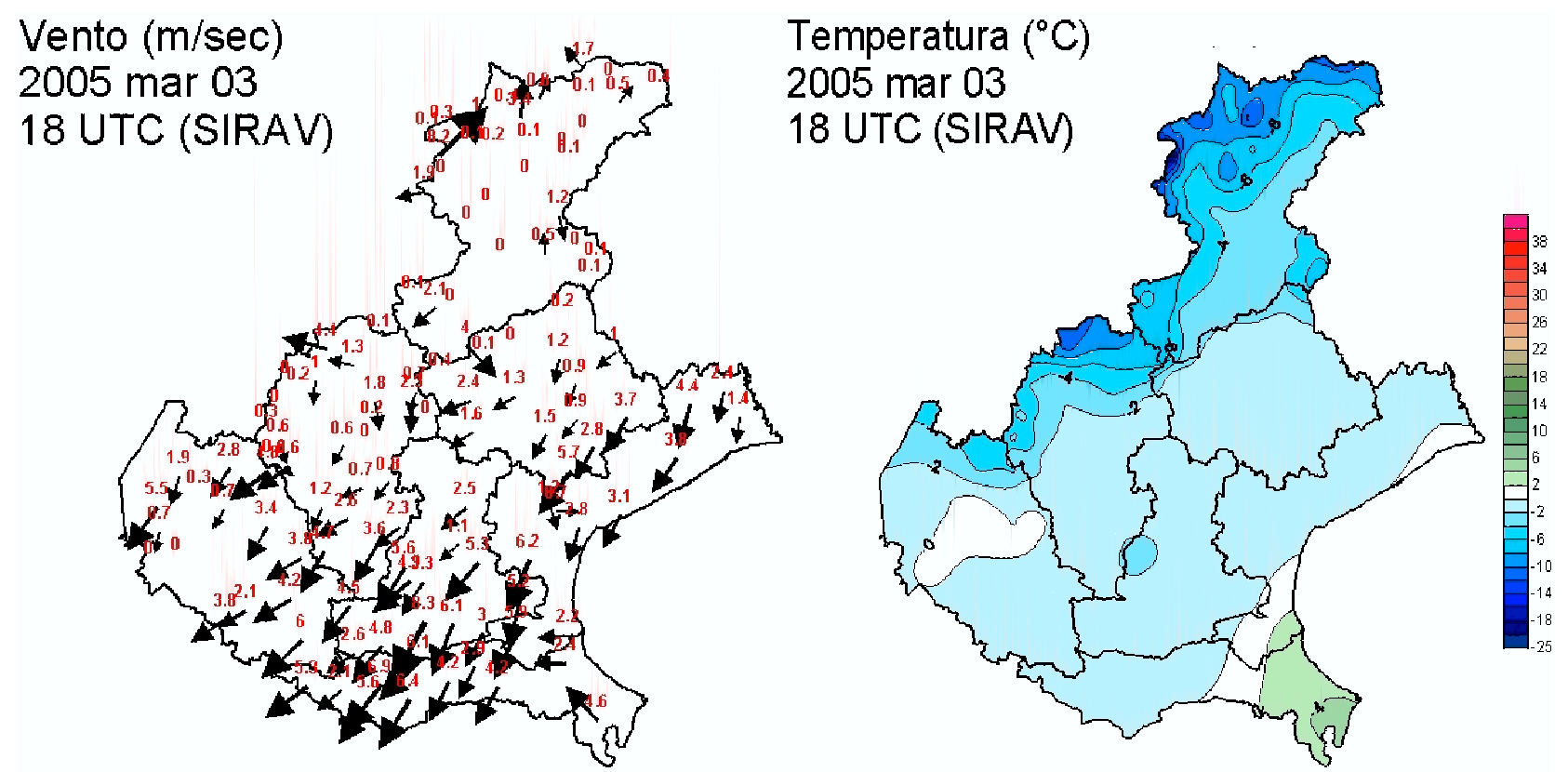

Fig. 4. ARPAV automatic weather station network data observed at 3 March 2005 18:00 UTC. The upper panel shows $v_{10} \mathrm{~m}$ (numbers denote wind speed in $\mathrm{m} / \mathrm{s}$ ), while the lower panel shows $T_{2 \mathrm{~m}}$ (color shadings, contour interval $2 \mathrm{~K}$ ). 

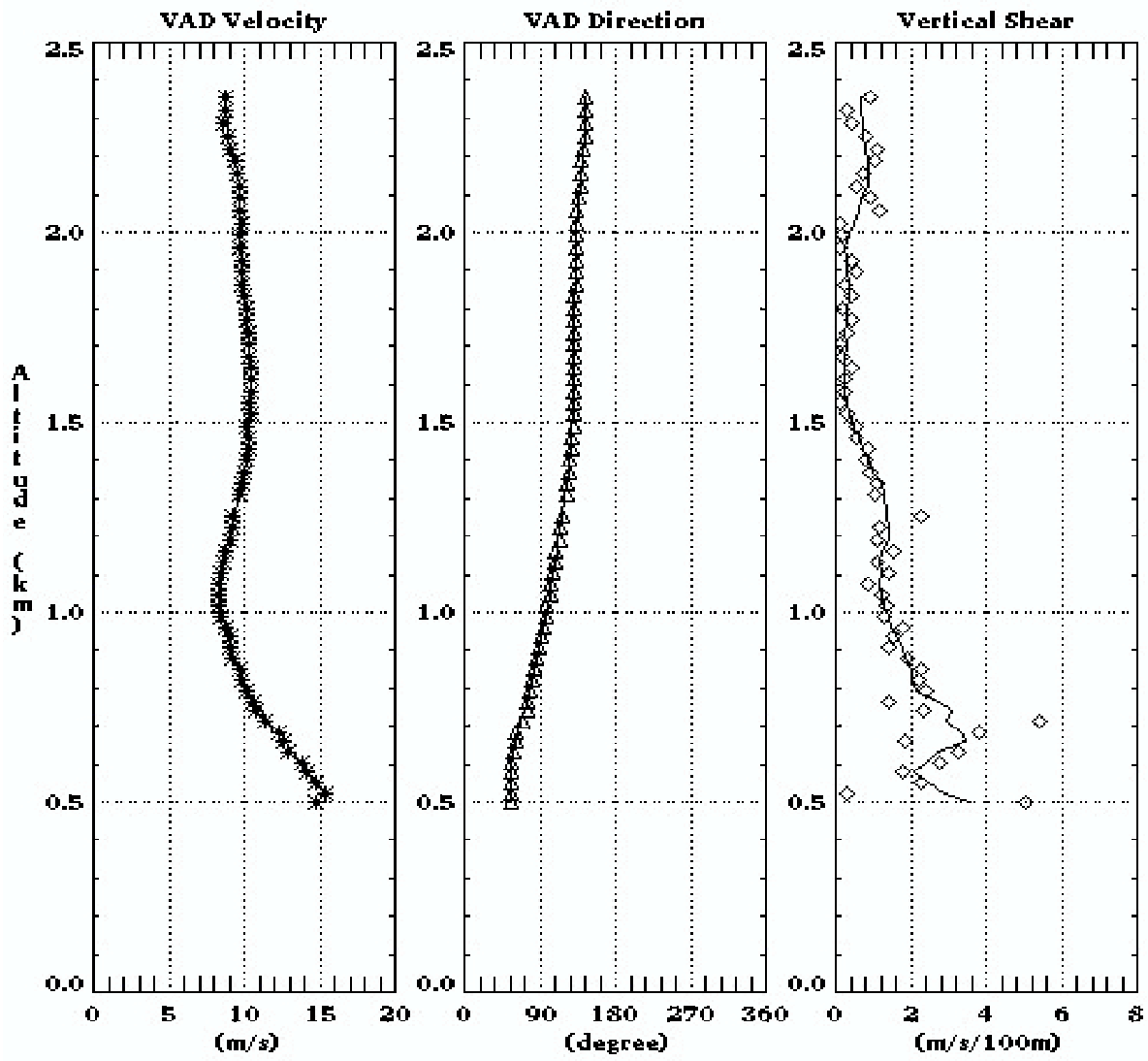

Fig. 5. ARPAV Mt. Grande Doppler radar velocity azimuth display (VAD). The panels denote from left to right wind speed (m/s), wind direction $\left({ }^{\circ}\right)$, and vertical wind shear $(\mathrm{m} / \mathrm{s} / 100 \mathrm{~m})$.

melting layer ahead of the orographic obstacle and prevents the snow from melting when reaching the ground;

- the precipitation distribution (not shown) exhibited a maximum upstream of the pre-alpine and Alpine barrier in the region of Vicenza;

- the high-resolution limited area model LAMI did successfully capture this mesoscale flow feature, while it was absent in the ECMWF global model forecast;

- an integrated meteorological observing system is crucial for monitoring such a situation.

The north-easterly flow analyzed in the lowest part of the troposphere over the Veneto plains in a situation of prevalent meridional synoptic flow features distinct mesoscale characteristics. Classical cases of Bora in the region of interest usually exhibit maximum wind speeds east and just downwind of the Dinaric Alps. Also, intensification of the Bora following the passage and south-eastward propagation of a northern Adriatic depression is quite common. Here, however, northeasterly surface winds in Trieste, a typical Bora site, were observerd to amount to about $5-6 \mathrm{~m} / \mathrm{s}$ averaged over the entire period of interest, whereas winds around $6 \mathrm{~m} / \mathrm{s}$ where observed on the south-western Veneto plains, for instance. The fact that in other typical Bora sites like Pula and Portoroz the wind was moderate and from the southeast (not shown, but see lower panel of Fig. 2) is another indicator that the north-easterly flow over Veneto is not part of a classical Bora configuration. In addition, the low pressure centre was still situated on the northern Adriatic during and right after the precipitation episode with the southerly flow forced over the cold air.

The overall southerly flow tagged "Sirocco" in Fig. 7 was moderate and seemed, at least partially, blocked by the Alps, resulting in a flow reversal at the lowest levels. Due to the geography in the area the flow deflection acquired a northeasterly component (Buzzi, 2004) which may have enhanced the moderate north-easterly flow on the Veneto plains tagged "Bora" in Fig. 7. Evaporative cooling associated with the precipitation forced over the cold air pool may have contributed to maintain and intensify the cold air and so prevent the warm air to advance inlands. As a matter of experience, propagation of the warm air up to the foothills of the prealpine chain is the way more frequent case in similar synoptic settings. However, this dynamical aspect needs further investigation, especially with respect to the characteristics of the pre-existing cold air pool and intensity and stratification of the meridional flow. Also, more such cases need to be identified and analyzed in order to undergird the findings.

Acknowledgements. The authors would like to thank Andrea 


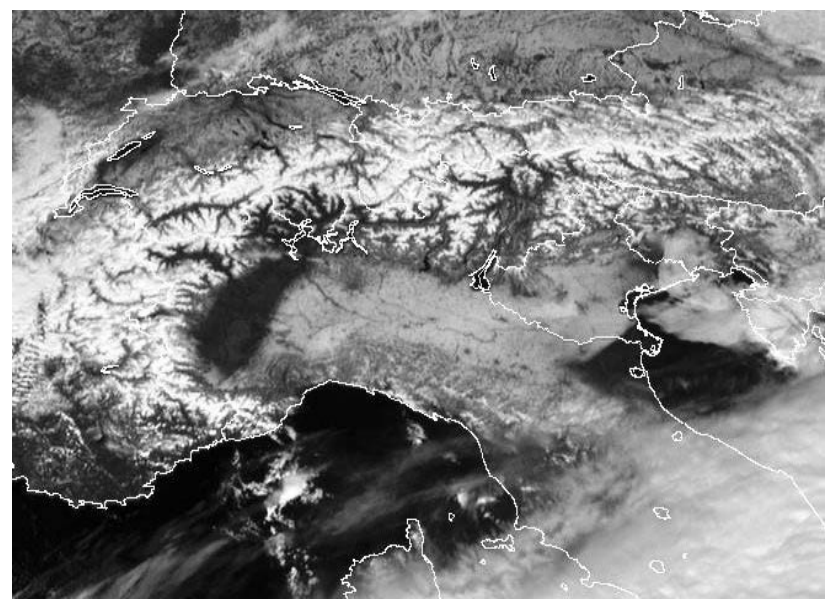

Fig. 6. Meteosat-8 high-resolution visible product HRV over northern Italy for 4 March 2005 12:00 UTC (obtained from EUMETSAT by way of the Italian Air Force Meteorological Service).

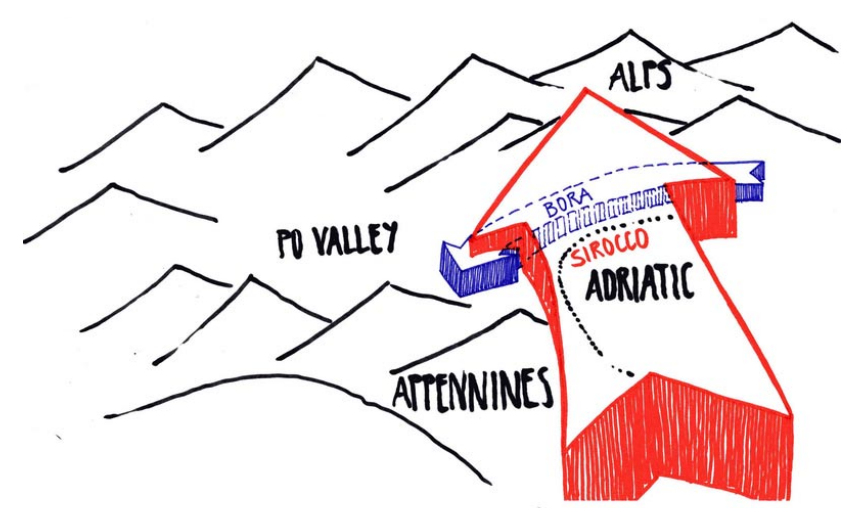

Fig. 7. Conceptual sketch of the flow situation. As described in the text, the cold air flow tagged "Bora" may be a combination of a Bora flow and a barrier jet originating from a flow reversal due to blocking of the warm air flow tagged "Sirocco".

Buzzi for pointing out the issue of the flow reversal, and Gabriele Formentini for preparing Meteosat- 8 and VAD images.

Edited by: V. Kotroni and K. Lagouvardos Reviewed by: anonymous referee

\section{References}

Bougeault, P., Binder, P., Buzzi, A., Dirks, R., Kuettner, J., Houze, R., Smith, R. B., Steinacker, R., and Volkert, H.: The MAP Special Observing Period, Bull. Am. Meteor. Soc., 82, 433-462, 2001.

Brzovic, N.: Factors affecting the Adriatic cyclone and associated windstorms, Contr. Atmos. Phys., 72, 1, 51-65, 1999.

Buzzi, A.: Heavy precipitation and Alpine orography, Proceedings of the International Workshop on timely warnings of heavy precipitation episodes and flash floods, Ljubljana, 21-22 October 2004, 12pp., 2004.

Doms, G. and Schättler, U.: A description of the nonhydrostatic regional model LM: Part I: Dynamics and numerics, http:// cosmo-model.org, 2004.

Doms, G., Förstner, J., Heise, E., Herzog, H.-J., Raschendorfer, M., Schrodin, R., Reinhardt, T., and Vogel, G.: A description of the nonhydrostatic regional model LM: Part II: Physical parametrization, http://cosmo-model.org, 2004.

Ivancan-Picek, B. and Tutis, V.: A case study of a severe Adriatic bora on 28 December 1992, Tellus, 48A, 357-367, 1996.

Miglietta, M. and Buzzi, A.: A numerical study of moist stratified flow regimes over isolated topography, Q. J. R. Meteorol. Soc., 130, 1749-1770, 2004. 